\title{
Examining the influences of tree-to-tree competition and climate on size-growth relationships in hydric, multi-aged Fraxinus nigra stands
}

\author{
Christopher E. Looney ${ }^{\text {a, }}$, Anthony W. D'Amato ${ }^{\text {b }}$, Shawn Fraver ${ }^{\text {c }}$, Brian J. Palik ${ }^{\text {d }}$, \\ Michael R. Reinikainen $^{\mathrm{e}}$
}

\footnotetext{
${ }^{a}$ University of Minnesota, Department of Forest Resources, St. Paul, MN 55108, USA, email: loone016@umn.edu

${ }^{\mathrm{b}}$ University of Vermont, Rubenstein School of Environment and Natural Resources, Burlington, VT 05095, USA, email: awdamato@uvm.edu

${ }^{c}$ University of Maine, School of Forest Resources, Orono, ME 04469, email: shawn.fraver@maine.edu

${ }^{\mathrm{d}}$ USDA Forest Service, Northern Research Station, Grand Rapids, MN 55744, USA, email: bpalik@fs.fed.us

${ }^{\mathrm{e}}$ University of Minnesota, Cloquet Forestry Center, Cloquet, MN 55720, USA, email: mike.reinikainen@gmail.com
}

${ }^{1}$ Corresponding Author: Christopher Looney (email: loone016@umn.edu) 


\section{I. Introduction}

2 Trees differentiate in growth rate and size during stand development, with implications

3 for long-term patterns of forest productivity, structural characteristics, and mortality (Oliver and

4 Larson, 1996). Differences in individual tree growth rates and sizes within forest stands may

5 reflect a number of factors including microsite characteristics, such as water availability

6 (Greenwood and Weisberg, 2008). In closed canopy stands in the absence of disturbance, the

7 degree of heterogeneity in growth rates and size can be greatly influenced by tree-tree

8 interactions, in particular, competition (Long et al., 2004; Oliver and Larson, 1996).

9 Retrospective studies of competition in forests have used neighborhood competition

10 indices, which characterize the growth of individual target trees based on the size and, in some

11 cases, the distance of competitors (Biging and Dobbertin, 1995; Canham et al., 2006, 2004;

12 Larocque, 2002). Incorporating information about the relative distance of competitors is

13 hypothesized to improve growth predictions in complex uneven-aged stands (Inoue et al., 2008),

14 although the results of previous research using distance-dependent indices are inconsistent

15 (Busing and Mailly, 2004). Competition indices can be used to supplement traditional measures

16 of stand density in order to better describe the nature of tree-tree interactions, including size

17 symmetry (Biging and Dobbertin, 1995; Canham et al., 2006, 2004; Larocque, 2002). When light

18 is a limiting resource, as in closed canopy stands, tree-tree competition often demonstrates partial

19 size asymmetry, with larger trees disproportionately suppressing the growth of smaller

20 individuals (Schwinning and Weiner, 1998). In contrast, competition for soil resources, which are

21 more diffuse and difficult to preempt, is more size-symmetric (Schwinning and Weiner, 1998),

22 with access of individual trees to resources directly proportional to size (Larocque, 2002). If not

23 offset by mortality, size-asymmetric interactions can increase growth rate variability within 
24 stands over time (Binkley, 2004), whereas size-symmetric competition evenly reduces individual

25 tree growth below potential levels (Weiner and Thomas, 1986). Size-asymmetric competition

26 may become increasingly symmetric later in stand development (Masaki et al., 2006), possibly as

27 a result of increasingly scarce soil resources. In drought-limited forests, competition may also

28 become inverse size-asymmetric, disproportionately impacting larger individuals (Biondi, 1996).

29 The onset of competition among trees early in stand development is typically understood

30 to coincide with peak net stand-level growth and leaf-area (Long et al., 2004). Declining net

31 stand-level growth following canopy closure contrasts with individual tree wood production,

32 which typically increases with age (Long et al., 2004; Stephenson et al., 2014). Changes in stand

33 growth and competitive interactions during stand development have been examined in terms of

34 size-growth relationship (SGR), to aid in understanding the association between tree size and

35 individual tree contributions to stand productivity (Castagneri et al., 2008; Metsaranta and

36 Lieffers, 2010; Pretzsch and Biber, 2010). SGR is a stand-level metric that infers from tree sizes

37 and growth rates the relative efficiency with which trees of differing sizes utilize available

38 resources (Castagneri et al., 2012). In addition to long-term trends, SGR may provide insights

39 into the effects of short-term fluctuations in stresses, such as extreme temperatures, drought, or

40 low site quality on growth inequality (Castagneri et al., 2012; Pretzsch and Dieler, 2010). Similar

41 to the patterns of size-symmetry used to characterize competition effects on individual trees,

42 SGR is considered asymmetric when larger trees in a stand grow at relatively higher rates,

43 symmetric when trees of all sizes grow at relatively similar rates, and inverse asymmetric when

44 smaller trees grow at relatively higher rates (Castagneri et al., 2012).

45 In mature stands, several studies have found evidence of inverse size-asymmetric SGR,

46 with smaller trees growing at higher rates than larger trees (Binkley et al., 2006; Castagneri et al., 
47 2012; Pretzsch and Biber, 2010), supporting the hypothesis that large trees decline in relative

48 growth as stands age (Binkley et al., 2006). However, research to date suggests inverse size

49 asymmetry does not necessarily emerge in unmanaged mature stands (Bradford et al., 2010; Doi

50 et al., 2010; Metsaranta and Lieffers, 2010; Nord-Larsen et al., 2006), may only occur in non-

51 clonal species (Binkley et al., 2006), or is only stable in stands with multilayered structures

52 (Castagneri et al., 2012). Inverse size-asymmetric SGR may stem from a size-related decline in

53 the efficiency of large trees or from a decline in individual tree competition for light or other

54 resources (Pretzsch and Biber, 2010), although no study to date has thoroughly investigated the

55 relationship between individual tree competition and stand-level SGR.

Furthermore, most research on tree-tree competition and SGR has focused on upland

57 systems. It is unclear if inferences from these studies extend to wetland forests. Seasonal

58 inundation in wetland forests poses particular challenges to tree growth (Kreuzwieser and

59 Rennenberg, 2014). Although nutrient inputs during flood events may offset stress (Odum,

60 1985), saturated soil conditions can reduce productivity (Megonigal et al., 1997), while

61 impairing tree nutrient status by restricting rooting depth (Baker et al., 2001). The few studies

62 examining competitive dynamics in wetland systems show varying results. For example, even-

63 aged Taxodium distichum L. (swamp cypress) stands display size-density and self-thinning

64 relationships similar to those in upland forests (Keim et al., 2010), while Minnesota Fraxinus

65 nigra Marsh (black ash) wetland forests show no evidence of competition based on an analysis

66 of neighborhood basal area (Benedict and Frelich, 2008). In general, tree growth is thought to be

67 less affected by drought in more hydric environments, due to the greater reliability of available

68 water (Dudek et al., 1998). However, in a harsh floodplain environment in Quebec, F. nigra

69 exhibited a lagged growth response to drought, with the seasonality of the drought determining 
70 whether the response was negative or positive (Tardif and Bergeron, 1993). No analysis to date

71 has looked at the influence of drought on SGR in hydric forests.

72 We retrospectively investigated the relationship of tree-tree competition, SGR, and

73 climate in northern Minnesota wetland forests dominated by F. nigra, an important tree species

74 in northeastern North America currently threatened by the invasive insect, emerald ash borer

75 (Agrilus planipennis, EAB; MacFarlane and Meyer, 2005). We took advantage of a detailed,

76 stem-mapped dataset of 1670 trees in five late-successional, multi-aged $F$. nigra stands to answer

77 the questions: 1) how do competitive interactions, particularly individual-level size symmetry,

78 influence individual-tree growth; 2) do late-successional F. nigra stands display inverse

79 asymmetric SGR; and 3) do short-term variations in drought influence SGR in F. nigra wetland

80 forests? We expected competition to be primarily size-symmetric, particularly at wetter sites

81 where higher abiotic stress would increase soil resource limitation. Given advanced stand age

82 and moderate shade tolerance of $F$. nigra, we further expected to find inverse-size asymmetric

83 SGR (i.e., disproportionately faster growth of smaller trees), especially at more severely flooded

84 sites and sites with more shade-tolerant competitor species. Lastly, given a hydrological regime

85 characterized by ponding and minimal sediment transport, we expected drought to increase both

86 individual large tree growth and SGR by reducing abiotic stress. Our overarching goal was to test

87 whether the combined results of individual-tree competition models and stand-level SGR could

88 provide deeper insights into growth and competition in F. nigra forests.

90 2. Material and Methods

912.1 Site description

92 We examined five late-successional, multi-aged, $F$. nigra-dominated forest stands, located 
93 on dispersed study sites in northeastern Minnesota (Figure 1). Climate is continental, with the

94 majority of precipitation occurring from May through September (PRISM Climate Group, 2015).

95

96

97

98 Soil varies from loam and sandy loam derived from glacio-fluvial or lacustrine parent materials

99

100

101

102

103

104

105

106

107

108

109

110

111

112

113

114

115

\section{Insert Figure 1 approximately here}

to clay and silty clay derived from glacio-lacustrine material (USDA Natural Resources

Conservation Service, 2013). A confining layer of clay results in poor soil drainage and ponding during the early part of the May to September growing season, with water levels declining to below the ground surface typically by mid-July on all but the wettest sites (USDA Natural Resources Conservation Service, 2013). Precipitation (especially snowmelt) and evapotranspiration are largely responsible for water table fluctuations, with only minimal shallow subsurface flow occurring (Slesak et al., 2014). Ponding duration is highest at Lake Williams, followed by Toimi Creek, Round Lake, Waskish Trail, and Kupcho Run. Due to soil and slight topographical differences, variations in ponding duration were not linked to variations in mean annual rainfall (Table 1).

Fraxinus nigra was the dominant tree species an all sites, averaging $77.30 \pm 2.7$ percent of basal area across the five study sites (Table 1). Other tree species varied by site. The most common tree species other than F. nigra were Tilia americana L. (American basswood) and Abies balsamea L. (balsam fir) at Kupcho Run, Betula alleghaniensis Britton (yellow birch) and Thuja occidentalis L. (northern white cedar) at Lake Williams, Ulmus americana L. (American elm) and A. balsamea at Round Lake, T. occidentalis and B. alleghaniensis at Toimi Creek, and A. balsamea and Picea glauca (Moench) Voss (white spruce) at Waskish Trail (Table 1). 


\section{Insert Table 1 approximately here}

\subsection{Field data collection}

We installed one 71.7 x $71.7 \mathrm{~m}$ (0.5 ha) plot per stand. Within each plot, we assessed all

121 living trees $\geq 10 \mathrm{~cm}$ diameter at breast height $(\mathrm{DBH})$ and recorded their species, $\mathrm{DBH}$, status

122 (live or dead), and Cartesian coordinates ( $\mathrm{x}$ and $\mathrm{y}$ ). We collected a single increment core to pith

123 when possible from all trees at $1.3 \mathrm{~m}$ above the ground, for a total of 1670 cored live trees. While

124 Visser (1995) recommends collecting a second core per tree at 90 degrees from the first to obtain

125 an accurate estimate of growth, the large number of sampled trees, given our desire to quantify

126 population-level growth, made this infeasible. We also sampled 147 standing snags but opted to

127 exclude them, as only 42 yielded measurable increment cores, species identification was

128 problematic, and uncertain preservation rates meant that extant deadwood could not serve as a

129 reliable sample of conditions beyond the most recent decades.

\subsection{Sample preparation}

132 Increment cores were prepared for analysis using standard dendrochronological

133 techniques (Speer, 2010). Finished cores were measured for annual ring width using a Velmex

134 measuring stage and visually cross-dated using the pointer-year method. We validated cross-

135 dating in the COFECHA program (Holmes, 1983). To account for radial asymmetry (Visser,

136 1995), we scaled growth records by the ratio of the summed ring widths to the estimated mean

137 inside-bark radius of the tree (Frelich, 2002), except where heart rot precluded obtaining full

138 cores. We used bark thickness equations for Lakes States trees published in Dixon and Keyser 
139 (2008) to estimate diameter inside bark. For the analysis of competition, raw ring widths were 140 converted to basal area increment (BAI) in the dplR package (Bunn, 2008) for R (R Core Team,

141 2013). For the analysis of growth asymmetry, we converted raw ring widths to annual biomass

142 increment. We used biomass allometric equations in Perala and Alban (1993) for all species,

143 which were developed in Minnesota for trees spanning the range of diameters in our samples.

144 The analysis of competition used BAI instead of biomass increment for consistency with other 145 studies (Fraver et al., 2014; Larocque, 2002; Wykoff, 1990); the relationship between BAI and 146 biomass was strongly linear $\left(\mathrm{R}^{2}=0.97\right)$.

151 target tree) and distance-independent competition indices (CIs) in order to further characterize 152 the nature of competition in these stands (Table 2). We were particularly interested in whether 153 competition was size-symmetric or asymmetric and distance-dependent or independent, and 154 consequently restricted our analysis to fairly simple CI formulae based on available DBH and 155 distance information. In the context of this paper, our uses of the terms size symmetry, size 156 asymmetry, and inverse size asymmetry are equivalent to Schwinning and Weiner's (1998) 157 perfect size symmetry, partial size asymmetry, and partial size symmetry, respectively. Index 1 is 158 simply the sum of competitor diameters within a given radius (Table 2). Indices 1 and 2 do not 159 consider target tree diameter and can thus be viewed as size-symmetric. Indices 2-5 include 160 information about competitor size and distance relative to the target tree and correspond to 161 Indices 9-12 in Rouvinen and Kuuluvainen (1997). Index 3 is Hegyi’s (1974) size-asymmetric 
162 index. Index 4 is also size-asymmetric but weights tree-tree distance heavily. Index 5 squares the

163 size ratio, which weights competitors that are larger than the target tree more heavily. Index 6 is a

164 distance-independent version of index 5. We also tested Lorimer's (1983) and Wykoff's (1990)

165 distance-independent indices, both of which are size-asymmetric but involve less intensive field 166 data collection and have proven effective in describing the nature of competition in a variety of

167 forest conditions (Fraver et al., 2014). As with the other CIs, we calculated Lorimer's (1983) and 168 Wykoff's (1990) indices based on focal tree neighborhoods rather than stand-level basal area or 169 sums of diameters.

173 A key step in using distance-dependent CIs is selecting a maximum search radius for 174 potential competitors (Biging and Dobbertin, 1995). While recent authors have used a nonlinear, 175 maximum-likelihood approach to estimate weighting factors for competitor size, distance, and 176 maximum distance (e.g., Canham et al., 2004), we opted to test these factors using different CIs 177 and search radii to characterize the nature of competition (Aakala et al., 2013). This approach 178 uses more traditional linear modeling that facilitates multi-model inference using information179 theoretic approaches (Burnham and Anderson, 2003). We initially constructed a model of log180 transformed 20-yr average BAI (1991-2010) vs. CIs pooled across all sites, with CIs calculated 181 based on search radii varying from 5 to $10 \mathrm{~m}$ in $1 \mathrm{~m}$ increments. We chose a 20 -yr average 182 because a previous study suggested shorter growth windows are more easily perturbed by 183 climatic factors (Busing and Mailly, 2004). We modeled growth only for target trees $\geq 10 \mathrm{~m}$ from 184 plot edge to avoid bias from unmeasured competitors. We found a search radius of $7 \mathrm{~m}$ was 
185 optimal (using pooled data) in terms of having the lowest value of Akaike's information criteria

186 in bivariate regression with BAI (AIC, Akaike 1974).

\subsubsection{Size-growth relationship}

We followed Metsaranta and Lieffer's (2010) approach for characterizing size-growth

190 relationships given its computational ease, ability to handle missing data over previous years,

191 and straightforward interpretation. Briefly, this approach (hereafter referred to as "SGR")

192 estimates the slope of the regression between present-year proportional growth increment

193 (individual-tree biomass increment relative to total stand biomass increment) and preceding-year

194 proportional tree size (individual-tree biomass relative to total stand biomass), both of which are

195 center log ratio-transformed (Aitchison, 1986). This transformation first relativizes within-tree

196 growth and then applies a log transformation over all trees (Aitchison, 1986), yielding a linear

197 relationship between increment and size over long time periods (Metsaranta and Lieffers, 2010).

198 A value of 1 indicates size-symmetry; values above and below 1 indicate size-asymmetry and

199 inverse size-asymmetry, respectively (Metsaranta and Lieffers, 2010). We confirmed SGR

200 linearity through exploratory analysis (data not shown). We opted to use total aboveground

201 biomass increment instead of volume, which has been used in previous studies (e.g., Metsaranta

202 and Lieffers, 2010), due to the availability of local biomass equations (Perala and Alban, 1993),

203 as well as the potential to account for shifts in aboveground growth allocation over time and for

204 varying wood density among species. We calculated the index for the 1951-2010 period, as

205 sample depth (number of trees) declined sharply in the 1940s. The index was calculated

206 separately for F. nigra, as well as for all species pooled to allow for examinations of species-

207 specific and population-level trends in SGR. 


\subsubsection{Climate}

210 We examined the relationship between annual variations in drought and SGR for each

211 site. We standardized 60-yr SGR chronologies at each site by fitting a 20-yr cubic spline with a

212 wave cutoff of 0.5. We used Palmer's drought severity index (PDSI, Palmer, 1965) as an

213 indicator of historical water availability. An integrated measure of precipitation and potential

214 evapotranspiration, PDSI has been widely used in dendro-climatological studies to represent

215 moisture stress (Speer, 2010). Positive PDSI values indicate above-average moisture; negative

216 values indicate moisture deficits. We obtained monthly PDSI records for the northern Minnesota

217 study area from the National Climatic Data Center (National Oceanic and Atmospheric

218 Administration, 2015). We also investigated SGR relationships with mean monthly precipitation 219 and maximum temperature records (PRISM Climate Group, 2015).

\subsubsection{Statistical modeling}

222 Our analyses included two organizational levels: individual tree-tree interactions and

223 stand-level SGR. For the analysis of individual tree-level growth, sites were analyzed

224 independently to examine within-site patterns, while we used the pooled dataset of trees across

225 all sites to model the general performance of the various CIs. In both cases, we examined the

226 relationship between $F$. nigra growth and tree size and competition, with average 20-yr BAI

227 (1992-2011) as the response variable. Non-F. nigra species were too scarce to separate

228 competitors by species. To address the fact that tree response to competition may vary with size

229 (Biondi, 1996; Canham et al., 2006), we included an end-year DBH x CI interaction term in the

230 full models. Square root and natural $\log$ transformations of BAI were applied when necessary to 
meet regression assumptions. Based on plots of raw data and model residuals, it was unnecessary

232 to transform Wykoff's (1990) index. All other CIs, as well as DBH, were natural log

233 transformed. We centered and scaled variables to place DBH and CI on comparable scales and

234 reduce multicollinearity.

235 We began the analysis of individual tree growth by building candidate models based on

236 expectations regarding the nature of tree-tree competition in multi-aged $F$. nigra stands. Our

237 analyses were structured to distinguish among competitive (negative CI effect), neutral (low AIC

238 support for models excluding CI), or facilitative (positive CI effect) tree-tree effects on growth.

239 For each CI, we began with a global model including the main effects of size and CI, plus an

240 interaction term to allow for the possibility that growth response to competition may vary with

241 tree size (as above). Based on the global model, we also derived models to evaluate the main

242 effects of CI and DBH both together and as univariate predictors. Models with the lowest AIC

243 values were considered the best approximating models in a given set, and we compared strength

244 of evidence for a given model based on its difference from the top model in a given set ( $\Delta$ AIC).

245 Candidate models within $\triangle \mathrm{AIC} \leq 2$ were considered as having a similar level of support for

246 being the best approximating model in a set (Burnham and Anderson, 2003). We further

247 compared models using Akaike's (1974) weights and weight ratios to construct confidence sets

248 of models with an evidence ratio within 1/8 of the highest-weight model (Burnham and

249 Anderson, 2003). For clarity, we only present the top within-site models included in the

250 confidence set at each site. Similarly, among the pooled data models, we also restrict our

251 presentation to confidence set models. We also present intercept-only null models for purposes of

252 comparison, in which BAI is solely a function of mean growth rate and spatial autocorrelation.

253 Given adjacency of trees within sites, we compared models both excluding and accounting for 
254 spatial autocorrelation of recent individual-tree growth. Spatially autocorrelative models

255 involved fitting an exponential variogram to model residuals to adjust regression estimates. This

256 approach helps control for microsite heterogeneity or shared history of minor disturbances that

257 may result in adjacent trees showing similar growth rates, regardless of biotic interactions

258 (Puettmann et al., 2009). Analysis of individual-site growth models was performed using

259 generalized least-squares (GLS) regression.

260 In contrast to individual-tree-level growth, for the stand-level metric, SGR, each site was

261 treated as representing a single sample unit. We examined within-site differences in SGR in

262 terms of type (calculated separately for F. nigra vs. all species combined), year, and year x type

263 interaction. We constructed a null intercept-only model, a global model incorporating main

264 effects and the interaction for each site, and simpler models of main effects and bivariate

265 relationships. We used AIC as described above to assess strength of evidence for each alternative.

266 Spatial autocorrelation was not a potential confounding factor in these analyses, as it was with

267 individual tree competition. However, because SGR represented time-series (1951-2010) data as

268 opposed to a single, periodic average, there was a possibility that temporal autocorrelation could

269 influence estimates. Autocorrelation function, partial autocorrelation, and model residuals plots

270 suggested SGR was an AR (1) process (SGR in the present year is positively correlated with

271 SGR of the previous year), which we modeled in the residual variance using generalized least

272 squares (GLS) modeling. We performed GLS modeling using the gls function in the nlme

273 package (Pinheiro et al., 2012) for R (R Core Team, 2013). Pooled data models included a

274 random site effect to stratify autocorrelation estimates; these models were performed using the

275 lme function in nlme.

276 The relationships between SGR and climate variables were examined using bootstrapped 
277 response function analysis in the R package bootres (Zang and Biondi, 2013). This procedure

278 reduces the dimensionality of multivariate monthly climate records through principle

279 components analysis (PCA), followed by regression of principle components (PC) on a given

280 chronology (Speer, 2010). Significance is then determined through a bootstrapped randomization

281 test with 1000 iterations. Given delays between precipitation and hydrological responses,

282 combined with known lagged F. nigra climate-growth responses (Tardif and Bergeron, 1993), we

283 extended the analysis window from January of the preceding year through the end of the current-

284 year growing season (September).

285

286

\section{Results}

\subsection{Individual tree growth and competition}

Basal area increment (BAI) over the 1992-2011 period for F. nigra subsampled for the

289 individual-tree growth models averaged $409.8 \pm 12.3 \mathrm{~mm}^{2} \mathrm{yr}^{-1}$ for all sites and was highest at

290 Kupcho Run $\left(618.2 \pm 136.5 \mathrm{~mm}^{2} \mathrm{yr}^{-1}\right)$ and Round Lake $\left(638 \pm 167 \mathrm{~mm}^{2} \mathrm{yr}^{-1}\right)$, intermediate at

291 Waskish Trail $\left(405.9 \pm 12.33 \mathrm{~mm}^{2} \mathrm{yr}^{-1}\right)$ and Lake Williams $\left(420.1 \pm 79.6 \mathrm{~mm}^{2} \mathrm{yr}^{-1}\right)$, and lowest

292 at Toimi Creek $\left(293.7 \pm 45.5 \mathrm{~mm}^{2} \mathrm{yr}^{-1}\right)$. Diameter at breast height (DBH) for the F. nigra

293 subsample averaged $22.2 \pm 15 \mathrm{~cm}$ for all sites and was highest at Round Lake $(30.6 \pm 4.5 \mathrm{~cm})$,

294 followed by Waskish Trail $(22.8 \pm 3.5)$, Toimi Creek $(20.7 \pm 2.6 \mathrm{~cm})$, Kupcho Run $(20.5 \pm 3.3)$,

295 and Lake Williams $(19.8 \pm 2.5)$. We tested for but found no evidence of facilitation.

296 There was evidence that tree size significantly influenced $F$. nigra growth at all sites,

297 while the most parsimonious models found that CI was an important predictor of individual tree

298 growth at all sites but Lake Williams (Table 3). End-year DBH was a significant, positive

299 predictor of past growth within the confidence set of all sites except Waskish Trail (Table 3). 
Furthermore, DBH had a larger standardized partial regression coefficient than either CI or

301 interaction terms in models for Kupcho Run, Lake Williams, and Round Lake (Table 3).

\section{Insert Table 3 approximately here} to predict growth, varied among sites (Table 3). The distance-independent Wykoff (1990) and Lorimer (1983) indices had substantial support at all sites. Wykoff's (1990) index was the best performing of the indices tested at Toimi Creek, Kupcho Run, and Waskish Trail, where support

309 for the best-performing alternative indices ranged from strong to negligible $(\triangle \mathrm{AIC}=3.1,0.4$, and $310>8$, respectively). Lorimer's (1983) index was the best performing at Lake Williams, and second-

311 best performing CI at Kupcho Run, Round Lake, and Toimi Creek ( $\triangle \mathrm{AIC}=3.1,0.0$, and 0.4,

312 respectively). Finally, the distance-independent index, CI-6, was the best-performing at Round

313 Lake, and third-best performing at Kupcho Run $(\triangle \mathrm{AIC}=4.69)$. Of the distance-dependent

314 indices, the most size asymmetric, CI-5, was the best supported but only included in the 315 confidence set of Waskish Trail $(\triangle \mathrm{AIC}=6.70)$. A bivariate model including Wykoff's (1990)

316 index was the most parsimonious model at Lake Williams, with competing regression models

317 lacking substantial AIC support ( $\triangle \mathrm{AIC}>8)$. The slope of the $\mathrm{CI}$ main effect was positive but 318 insignificant in models at Lake Williams.

319 With the exception of Waskish Trail, CI influenced growth both as a main effect and 320 through interaction with DBH (Table 3). Within the range of the data, growth effects of CI varied

321 from almost neutral in small trees to negative with increasing size in larger trees (Figure 2). At

322 Kupcho Run, Round Lake, and Waskish Trail, CI had a negative main effect, while also

323 interacting negatively with increasing DBH, which suggests CI had negative growth impacts that 
324 became more severe with increasing target tree size. At Lake Williams, the confidence set

325 included a weak, positive interaction effect in two less-supported models, suggesting growth

326 increased with CI, but at a faster rate when target tree size was larger. Models for Round Lake

327 and Toimi Creek included the largest interaction effects.

\section{Insert Figure 2 approximately here}

The best-performing model by CI based on pooled data included CI, DBH, and the CI x

332 DBH interaction (Table 3). Index 6 had the highest performance based on AIC, with Lorimer's

333 and Wykoff's indices also having substantial support ( $\triangle \mathrm{AIC}=1.06$ and 2.68, respectively). In all

334 cases, the main effect of DBH had the largest standardized partial regression coefficient,

335 followed distantly by CI and the CI x DBH interaction, and had greater significance for models

336 with high AIC support. The DBH x CI coefficient also declined but remained significant in the

337 model using Wykoff's index.

\subsection{Size-growth relationships}

For the 1952-2011 period, SGR averaged $0.58 \pm 0.001$ for all species combined (Figure

341 3). Round Lake showed the highest all-species SGR at $0.64 \pm 0.01$, followed by Lake Williams

342 (0.62 \pm 0.01$),$ Kupcho Run (0.61 \pm 0.01$)$, Waskish Trail $(0.54 \pm 0.01)$, and Toimi Creek $(0.51 \pm$

343 0.02). SGR calculated for F. nigra-only was highest at Round Lake at $0.85 \pm 0.01$, followed by

344 Kupcho Run (0.63 \pm 0.02$)$, Lake Williams $(0.63 \pm 0.01)$, Waskish Trail $(0.62 \pm 0.01)$, and Toimi

345 Creek $(0.58 \pm 0.01)$. At Waskish Trail, a plausible model including SGR type (F. nigra-only vs.

346 all species combined) suggested SGR was marginally higher for the F. nigra component ( $\mathrm{F}=14.7$, 
$347 \mathrm{p}<0.001$; Table 4), although this model had less AIC support than the Round Lake intercept-only

348 model $(\mathrm{F}=3.17, \mathrm{p}=0.078, \Delta \mathrm{AIC}=4.1)$. At Round Lake, there was evidence of a difference in type

349 of SGR, but this model had equivalent AIC support to the null model for the site.

Insert Figure 3 approximately here

Although not as well supported as intercept-only models, there was model support for a

354 decline in SGR over time at Toimi Creek $(\mathrm{F}=20.4, \mathrm{p}<0.001, \Delta \mathrm{AIC}=6.32$, Figure 3) and Kupcho

355 Run $(\mathrm{F}=14.65, \mathrm{p}<0.001, \Delta \mathrm{AIC}=5.98)$. There was minimal evidence for an SGR type $\mathrm{x}$ year

356 interaction $(\triangle \mathrm{AIC}>8)$ at any site.

Insert Table 4 approximately here

3.4. Climate

Due to inconsistent and generally insignificant relationships between SGR, temperature,

362 and precipitation across sites, as well as the lack of consistent trends in adjacent months, we

363 omitted these variables in favor of PDSI. We found significant $(\mathrm{p}<0.05)$ but tenuous relationships

364 between F. nigra SGR and PDSI for certain months at three of the five sites (Figure 4). Fraxinus

365 nigra SGR increased in years in which there was greater moisture availability in the winter of the

366 previous year, as evidenced by the positive response functions for previous February PDSI at

367 Lake Williams, and previous January- February-March PDSI at Waskish Trail. SGR for all

368 species increased at Round Lake in response to previous February PDSI. The PDSI response of

369 all-species-SGR was equivalent to that of $F$. nigra SGR at all other sites. At Round Lake, 
370 F. nigra SGR was lower in years with greater moisture availability during the preceding June and

371 July, but was not responsive to preceding June-July PDSI. We did not find any significant

372 SGR/PDSI relationships at Kupcho Run or Toimi Creek, and SGR did not vary significantly with 373 current year PDSI at any site.

Insert Figure 4 approximately here

377 4. Discussion

378 4.1 Individual-tree growth and competition

379 At the individual tree level, we found support for the continued importance of

380 competition in the late-successional F. nigra stands we sampled. While the importance of

381 competition varied substantially by site, competition was universally best described in terms of

382 the relationship between target tree size and the size of neighboring trees, independent of

383 neighbor tree distance. Given that spatial point pattern analysis showed irregular tree spacing on

384 three of our five late-successional F. nigra study sites (D'Amato, unpublished data), this result

385 contradicts the theory that distance-dependent CIs can better predict growth in complex, uneven-

386 aged, irregularly spaced stands (Inoue et al., 2008). Our finding confirms the observation of

387 previous researchers that distance-dependent CIs do not consistently improve growth predictions

388 compared to distance-independent CIs (Busing and Mailly, 2004). The inconsistent performance

389 of distance-dependent CIs suggests that the benefits of distance information in growth modeling

390 may vary substantially between systems (Aakala et al., 2013; Busing and Mailly, 2004).

391 As expected in our mature, predominantly closed-canopy stands (Schwinning and Weiner,

392 1998), we found greater support for size-asymmetric indices (i.e., large trees disproportionately 
393 suppressing the growth of smaller trees), especially the distance-independent Lorimer's (1983),

394 Wykoffs (1990), and CI-6 indices, than for size- symmetric indices. Of the size-asymmetric,

395 distance independent indices, CI-6, which assumes competition is more highly asymmetric by

396 squaring the ratio between competitor and target DBH, had better support than Lorimer's index

397 in pooled data models. The low performance of the size-symmetric, distance-independent CI-1

398 across all sites suggests belowground competition is of secondary importance in these stands, as

399 size-asymmetric competition in plants is frequently interpreted as reflecting light limitation

400 (Weiner, 1990). Unfortunately, the lack of young, even-aged stands in the dataset prevented us

401 from testing whether the degree of size-asymmetrical competition (Schwinning and Weiner,

402 1998) decreases with stand age, as suggested by Masaki et al., (2006).

403 In contrast to several previous upland forest studies (Canham et al., 2006, 2004; Gómez-

404 Aparicio et al., 2011), we found individual tree response to competition increased with tree size

405 at most sites. Biondi (1996) inferred a similar process in multi-aged Pinus ponderosa Laws.

406 (ponderosa pine), where old-growth trees show evidence of decline in response to historical

407 increases in young cohort density. We propose several non-exclusive hypotheses to account for

408 this finding. Higher responsiveness to competition as expressed in slowed growth rates in larger

409 trees may reflect ontogenetic declines in shade tolerance (Valladares and Niinemets, 2008) or

410 rising respiration costs with size (King, 1990). In addition, taller trees are subject to greater wind

411 stress; thus crown abrasion, resulting in reduced leaf area, could increase with canopy position

412 (Oliver and Larson, 1996). Nevertheless, if large trees are indeed more responsive to size-

413 asymmetric competition, the effect is offset by the fact that relatively larger neighbors were

414 uncommon compared to smaller trees (Coomes and Allen, 2007).

415 Individual-tree growth models indicated competition was likely an important process at 
416 all sites but Lake Williams, but tree size for the most part appeared to be a stronger indicator of

417 growth, with DBH frequently having the highest standardized partial regression coefficient. Our

418 finding of a positive relationship between BAI and DBH is corroborated by earlier work by

419 Benedict and Frelich (2008). The strong positive relationship between tree size and growth is

420 also consistent with general patterns typical of upland forest types, where individual tree BAI

421 continues to increase with size (Long et al., 2004; Stephenson et al., 2014). Despite taking

422 measures to assure limited multicollinearity in our models, target tree size was both an indicator

423 of short-term periodic growth and an outcome of long-term tree-tree interactions that confounds

424 analyses through correlation with CI (Biging and Dobbertin, 1995; Larocque, 2002).

425 We note that microsite variation may have reduced the importance of competition in this

426 study. The increased response of large trees to competition at some sites may be spurious if $F$.

427 nigra preferentially establishes on more suitable microsites, where small trees could display

428 rapid growth despite locally high tree densities. Additionally, a lack of significant evidence of

429 competition at Lake Williams and low partial regression coefficients at other sites could suggest

430 trees are unable to fully occupy available growing space. Similarly, low-quality microsites may

431 also have confounded our results, as trees on poor microsites face high abiotic stress despite

432 having few neighbors (Greenwood and Weisberg, 2008).

$434 \quad 4.2$ Size-growth relationship

435 At the stand level, SGR was consistently less than 1:1 at all sites and showed evidence of 436 inverse-size asymmetry (i.e., smaller trees growing faster), as expected given the advanced stand 437 age. Furthermore, SGR appeared to be either stable or declining over the preceding 60 years. Our 438 results support Binkley's (2004) prediction that smaller trees grow disproportionately faster than 
439 larger trees in mature stands, based on a model developed for dryer forest types. In addition, the

440 inverse-size asymmetric SGRs found in this study are consistent with Castagneri et al. (2012),

441 who found SGR <1 in an older stand of P. abies, as well as with the results of studies that found

442 faster growth of smaller relative to larger trees in mature, multilayered stands of other species

443 (Binkley et al., 2006; Ex and Smith, 2014). A caveat of retrospectively reconstructing SGR is

444 that long-term patterns may be obscured by past tree mortality, which we could not account for

445 due to rapid decay of dead trees. A modeling study suggests unaccounted mortality may obscure

446 stand-level growth trends (Foster et al., 2014), but to our knowledge mortality has not been

447 investigated in the context of SGR.

$448 \quad$ Our results suggest that multi-aged $F$. nigra stands may exhibit inverse-size asymmetric

449 SGR, even as individual trees compete asymmetrically for light late into stand development.

450 However, in terms of the hypothesis that inverse size-asymmetric-SGR in mature stands reflects

451 declining importance of light competition (Doi et al., 2010; Metsaranta and Lieffers, 2010;

452 Pretzsch and Biber, 2010), we found contradictory evidence in individual-tree growth models. In

453 agreement with this hypothesis, we found a lack of strong evidence of competition at Lake

454 Williams, where the most parsimonious model suggested growth was directly proportional to tree

455 size. Yet overall, we found greater support for size asymmetric indices both within and among

456 sites. While we would have expected higher performance of size-symmetric CI-2, given the

457 prevalence of inverse size-asymmetric SGR, CIs based on above-ground tree attributes may be

458 poor indicators of diffuse below-ground processes (Larocque, 2002). In addition, Pretzsch and

459 Biber (2010) note that large, inefficient trees in mature stands may depress SGR, even as small

460 trees face intense competition. Inverse size-symmetric SGR in this study more likely reflects

461 declining overstory efficiency, as opposed to competitive interactions between canopy layers. 
462 Our use of biomass in estimating SGR may also exaggerate declining efficiency compared with

463 SGR based on leaf area index (Ex and Smith, 2014). However, while the individual-tree and

464 SGR analyses differ in terms of growth metric (BAI vs. biomass increment, respectively), the

465 strong relationship between biomass increment and BAI suggests this discrepancy was not

466 responsible for the sometimes contradictory results of these analyses.

467 At Round Lake and Waskish Trail, we found evidence that SGR for $F$. nigra alone was

468 higher than for all species combined. With the exception of T. americana, A. balsamea, $P$.

469 glauca, and P. tremuloides at the Kupcho Run site, non-F. nigra species were relegated to lower

470 crown classes. The possible decline in SGR when including these species further suggests large

471 F. nigra are growing relatively inefficiently. At Round Lake and Waskish Trail, which showed

472 the greatest contrast between all-species and F. nigra SGR, the more shade-tolerant A. balsamea

473 and U. americana were present in lower strata. Binkley et al. (2006) report similar patterns in

474 their analysis of growth dominance in Rocky Mountain P. tremuloides stands with and without

475 conifer understories. Light partitioning between an intolerant upper strata and tolerant lower

476 strata may increase stand productivity as well as well as depress SGR (Binkley et al., 2006;

477 Pretzsch, 2005).

478 The patterns observed in our competition models and analyses of SGR could also reflect

479 recent periods of canopy disturbance in these ecosystems. In particular, many of the sites

480 contained a minor $U$. americana component in the canopy prior to the arrival of Dutch elm

481 disease (Ophiostoma novo-ulmi Brasier) in northern Minnesota in the early 1980s. Analyses of

482 growth releases and tree recruitment in these stands indicate significant periods of canopy

483 disturbance in the 1980 s in response to the loss of the $U$. americana component (D'Amato et al.

484 unpublished data). As a result, smaller trees occupying gaps may have affected size-related 
patterns in tree growth response to competition. In addition, following periods of drought in the

486 early 2000s, declines in crown condition and vigor have been recently observed in Minnesota $F$.

487 nigra stands (Palik et al., 2011). Crown dieback is particularly pronounced in large, old F. nigra

488 on wet sites and may account in part for inverse asymmetric SGR. While the etiology of this

489 phenomenon is not entirely understood, competition among large trees could contribute to lower

490 vigor and SGR. We found evidence of increasing growth responsiveness to CI with size at Toimi

491 Creek and Round Lake. Loss of upper canopy cover also reduces SGR by promoting growth in

492 lower canopy layers. However, given that sapling F. nigra appear also to be affected by canopy

493 dieback in stands showing overstory decline, albeit to a lesser degree than mature trees (Palik et

494 al., 2012), F. nigra decline may be more likely to promote increased growth of other species.

495

4.3 Climate

Studies of climate-SGR relationships in upland forests have found that short-term

498 variations in SGR reflect changes in abiotic stressors, such as climate and pollution (Pretzsch and

499 Dieler, 2010); while others have been inconclusive (Metsaranta and Lieffers, 2010). Our results

500 suggest that, when significant, moisture deficits as indicated by PDSI appear to influence the

501 following year's SGR in some F. nigra stands. While the correlation between lagged SGR and

502 precipitation was weakly significant for only three of the five sites that we studied, our finding is

503 consistent with a previous study that assessed $F$. nigra growth, but not SGR, in a harsher

504 floodplain setting in Quebec (Tardif and Bergeron, 1993). There, researchers found growth was

505 negatively correlated with precipitation in the preceding spring and positively correlated with

506 precipitation in the preceding July (Tardif and Bergeron, 1993). The authors suggested lagged $F$.

507 nigra growth-climate relationships could reflect the effects of moisture availability on bud 
508 formation (Tardif and Bergeron, 1993). Finally, we note that the inability to account for trees that

509 died before the start of measurement likely had an unknown impact on the results of the climate

510 analyses.

\section{IV. Conclusions}

513 We found evidence of competition within the five late-successional multi-aged F. nigra

514 stands we studied. The mode of competition appeared to be size-asymmetric, and distance-

515 dependent indices were less accurate predictors of growth than distance-independent ones.

516 Competition was useful for predicting growth at all sites, although much less important at the

517 wettest site. On sites where competition was important to explaining patterns in growth, trees

518 appeared increasingly responsive to competition with size, and size was a more accurate

519 predictor of growth than competition on all sites. The multi-aged F. nigra stands showed

520 consistent patterns of inverse size-asymmetric SGR (i.e., competition disproportionately

521 impacting larger individuals) that were generally consistent with previous observations of mature

522 upland forests. The simultaneous presence of size-asymmetric competition suggests declines in

523 large tree production efficiency are responsible for inverse asymmetric SGR in these stands.

524 Recruitment of vigorous, shade-tolerant species, especially following Dutch elm disease in the

525 1980s, as well as a disease-decline complex may have accentuated declining SGR in recent

526 decades. Moisture-deficit effects on SGR were sometimes evident but weak on both more mesic

527 and extremely wet sites.

$528 \quad$ Our results are consistent with past silvicultural experience with $F$. nigra, which suggests

529 multiaged management is preferable for promoting ecosystem resilience in these forests

530 (Erdmann et al., 1987). In particular, stands with mixtures of shade-tolerant species, such as $U$. 
531 americana or A. balsamea, are potentially more productive than pure stands, and the

532 combination of productivity and diversity may promote resilience following EAB invasion. The

533 development of inverse asymmetric SGR in multi-aged F. nigra stands indicates that lower

534 cohorts can grow efficiently under partial shade, a general requirement for efficient management

535 under selection systems. Unfortunately, EAB invasion may render long-term silvicultural

536 experiments involving mature $F$. nigra infeasible in coming decades. However, managers may

537 expect shade-tolerant, non- $F$. nigra species to respond positively to overstory loss, providing

538 decreased evapotranspiration from $F$. nigra tree loss does not prohibitively increase site moisture.

539 Based on our results, it appears large tree growth in some F. nigra stands benefits from winter

540 precipitation, while other stands may experience deleterious effects from heavy summer rains. As

541 a result, managers may expect declines in large tree growth in some post-EAB stands should

542 summer moisture availability increase as a result of reduced evapotranspiration following the

543 loss of F. nigra.

544

545 Acknowledgements

546 Funding for this study was provided by the Minnesota Environmental and Natural

547 Resources Trust Fund; the Frederick and Philip Noel Knorr and Northwest Paper Foundation

548 Fellowships through the University of Minnesota, Department of Forest Resources; and the

549 USDA Forest Service, Northern Research Station. We are grateful to the Chippewa National

550 Forest for providing logistical support and Kyle Gill, Paul Klockow, and Nick Jensen for

551 assistance with field sampling.

552

553 


\section{References}

555 Aakala, T., Fraver, S., D’Amato, A.W., Palik, B.J., 2013. Influence of competition and age on tree growth in structurally complex old-growth forests in northern Minnesota, USA. For. Ecol. Manag. 308, 128-135. doi:10.1016/j.foreco.2013.07.057

Aitchison, J., 1986. The Statistical Analysis of Compositional Data. Springer Netherlands, Dordrecht.

Akaike, H., 1974. A new look at the statistical model identification. IEEE Trans. Autom. Control 19, 716-723. doi:10.1109/TAC.1974.1100705

Baker, T.T., Conner, W.H., Lockaby, B.G., Stanturf, J.A., Burke, M.K., 2001. Fine Root Productivity and Dynamics on a Forested Floodplain in South Carolina. Soil Sci. Soc. Am. J. 65, 545. doi:10.2136/sssaj2001.652545x

Benedict, M.A., Frelich, L.E., 2008. Site factors affecting black ash ring growth in northern Minnesota. For. Ecol. Manag. 255, 3489-3493. doi:10.1016/j.foreco.2008.02.029

Biging, G.S., Dobbertin, M., 1995. Evaluation of Competition Indices in Individual Tree Growth Models. For. Sci. 41, 360-377.

Binkley, D., 2004. A hypothesis about the interaction of tree dominance and stand production through stand development. For. Ecol. Manag. 190, 265-271. doi:10.1016/j.foreco.2003.10.018

Binkley, D., Kashian, D.M., Boyden, S., Kaye, M.W., Bradford, J.B., Arthur, M.A., Fornwalt, P.J., Ryan, M.G., 2006. Patterns of growth dominance in forests of the Rocky Mountains, USA. For. Ecol. Manag. 236, 193-201. doi:10.1016/j.foreco.2006.09.001

Biondi, F.F., 1996. Decadal-scale dynamics at the Gus Pearson Natural Areas: evidence for inverse (a)symmetric competition? Can. J. For. Res. J. Can. Rech. For. 26, 1397-1406. 
doi:10.1139/x26-156

578 Bradford, J.B., D’Amato, A.W., Palik, B.J., Fraver, S., 2010. A new method for evaluating forest thinning: growth dominance in managed Pinus resinosa stands. Can. J. For. Res. 40, 843-

Bunn, A.G., 2008. A dendrochronology program library in R (dplR). Dendrochronologia 26, 849. doi:10.1139/X10-039

Burnham, K.P., Anderson, D.R., 2003. Model Selection and Multimodel Inference: A Practical Information-Theoretic Approach, 2nd ed. Springer-Verlag, New York.

Busing, R.T., Mailly, D., 2004. Advances in spatial, individual-based modelling of forest dynamics. J. Veg. Sci. 15, 831-842. doi:10.1111/j.1654-1103.2004.tb02326.x

Canham, C.D., LePage, P.T., Coates, K.D., 2004. A neighborhood analysis of canopy tree

Canham, C.D., Papaik, M.J., Uriarte, M., McWilliams, W.H., Jenkins, J.C., Twery, M.J., 2006. competition: effects of shading versus crowding. Can. J. For. Res. 34, 778-787. doi:10.1139/x03-232 Neighborhood Analyses Of Canopy Tree Competition Along Environmental Gradients In New England Forests. Ecol. Appl. 16, 540-554. doi:10.1890/1051-

Castagneri, D., Nola, P., Cherubini, P., Motta, R., 2012. Temporal variability of size-growth relationships in a Norway spruce forest: the influences of stand structure, logging, and climate. Can. J. For. Res. 42, 550-560. doi:10.1139/x2012-007

Castagneri, D., Vacchiano, G., Lingua, E., Motta, R., 2008. Analysis of intraspecific competition in two subalpine Norway spruce (Picea abies (L.) Karst.) stands in Paneveggio (Trento, Italy). For. Ecol. Manag. 255, 651-659. doi:10.1016/j.foreco.2007.09.041 
600 Coomes, D.A., Allen, R.B., 2007. Effects of size, competition and altitude on tree growth. J.

$601 \quad$ Ecol. 95, 1084-1097. doi:10.1111/j.1365-2745.2007.01280.x

602 Dixon, G.E., Keyser, C.E., 2008. Lake States (LS) Variant Overview: Forest Vegetation

603 Simulator, Internal Rep. USDA Forest Service, Forest Management Service Center, Fort

604 Collins, CO.

605 Doi, B.T., Binkley, D., Stape, J.L., 2010. Does reverse growth dominance develop in old

606

607 plantations of Eucalyptus saligna? For. Ecol. Manag., Productivity in Tropical Plantations

608 Dudek, D.M., McClenahen, J.R., Mitsch, W.J., 1998. Tree Growth Responses of Populus

609

610

611 259, 1815-1818. doi:10.1016/j.foreco.2009.05.031

612

613

614

615 deltoides and Juglans nigra to Streamflow and Climate in a Bottomland Hardwood Forest in Central Ohio. Am. Midl. Nat. 140, 233-244. doi:10.1674/0003-

0031(1998)140[0233:TGROPD]2.0.CO;2

Erdmann, G.G., Crow, T.R., Peterson Jr, R.M., Wilson, C.D., 1987. Managing black ash in the Lake States. Gen. Tech. Rep. NC-115, USDA Forest Service, North Central Forest Experimental Station, St. Paul, MN.

Ex, S.A., Smith, F.W., 2014. Wood production efficiency and growth dominance in multiaged and even-aged ponderosa pine stands. For. Sci. 60, 149-156. doi:10.5849/forsci.12-010

Fraver, S., D’Amato, A.W., Bradford, J.B., Jonsson, B.G., Jönsson, M., Esseen, P.-A., 2014. Tree growth and competition in an old-growth Picea abies forest of boreal Sweden: influence of tree spatial patterning. J. Veg. Sci. 25, 374-385. doi:10.1111/jvs.12096 
623 Frelich, L.E., 2002. Forest Dynamics and Disturbance Regimes: Studies from Temperate

624 Evergreen-Deciduous Forests. Cambridge University Press.

625 Gómez-Aparicio, L., García-Valdés, R., Ruíz-Benito, P., Zavala, M.A., 2011. Disentangling the

626 relative importance of climate, size and competition on tree growth in Iberian forests:

627 implications for forest management under global change. Glob. Change Biol. 17, 2400-

$628 \quad$ 2414. doi:10.1111/j.1365-2486.2011.02421.x

629 Greenwood, D.L., Weisberg, P.J., 2008. Density-dependent tree mortality in pinyon-juniper

630 woodlands. For. Ecol. Manag. 255, 2129-2137. doi:10.1916/j.foreco.2007.12.048

631 Hegyi, F., 1974. A simulation model for managing jack-pine stands. Growth Models Tree Stand $632 \quad$ Simul. 74-90.

633 Holmes, R.L., 1983. Computer-Assisted Quality Control in Tree-Ring Dating and Measurement. Tree-Ring Bull. 43, 69-78.

635 Inoue, S., Shirota, T., Mitsuda, Y., Ishii, H., Gyokusen, K., 2008. Effects of individual size, local competition and canopy closure on the stem volume growth in a monoclonal Japanese cedar (Cryptomeria japonica D. Don) plantation. Ecol. Res. 23, 953-964.

641 King, D.A., 1990. The Adaptive Significance of Tree Height. Am. Nat. 135, 809-828. doi:10.1007/s11284-008-0462-8

Keim, R.F., Dean, T.J., Chambers, J.L., Conner, W.H., 2010. Stand density relationships in baldcypress. For. Sci. 56, 336-343.

643 Kreuzwieser, J., Rennenberg, H., 2014. Molecular and physiological responses of trees to waterlogging stress. Plant Cell Environ. 37, 2245-2259. doi:10.1111/pce.12310

645 Larocque, G.R., 2002. Examining Different Concepts for the Development of a Distance- 

Data Differing in Initial Stand Density. For. Sci. 48, 24-34.

Long, J.N., Dean, T.J., Roberts, S.D., 2004. Linkages between silviculture and ecology: examination of several important conceptual models. For. Ecol. Manag. 200, 249-261.

Lorimer, C.G., 1983. Tests of age-independent competition indices for individual trees in natural

MacFarlane, D.W., Meyer, S.P., 2005. Characteristics and distribution of potential ash tree hosts hardwood stands. For. Ecol. Manag. 6, 343-360. for emerald ash borer. For. Ecol. Manag. 213, 15-24.

Masaki, T., Mori, S., Kajimoto, T., Hitsuma, G., Sawata, S., Mori, M., Osumi, K., Sakurai, S., Seki, T., 2006. Long-term growth analyses of Japanese cedar trees in a plantation: neighborhood competition and persistence of initial growth deviations. J. For. Res. 11, 217-225. doi:10.1007/s10310-005-0175-6

Megonigal, J.P., Conner, W.H., Kroeger, S., Sharitz, R.R., 1997. Aboveground production in southeastern floodplain forests: a test of the subsidy-stress hypothesis. Ecology 78, 370384.

Metsaranta, J.M., Lieffers, V.J., 2010. Patterns of inter-annual variation in the size asymmetry of growth in Pinus banksiana. Oecologia 163, 737-745. doi:10.1007/s00442-009-1559-7

National Oceanic and Atmospheric Administration, 2015. National Climatic Data Center: Minnesota Climate Division 2 [WWW Document]. URL http://www1.ncdc.noaa.gov/pub/data/cirs/ (accessed 7.10.15). individual beech trees. Can. J. For. Res. 36, 418-425. doi:10.1139/x05-255 
Odum, E.P., 1985. Trends Expected in Stressed Ecosystems. BioScience 35, 419-422. doi:10.2307/1310021

671 Oliver, C.D., Larson, B.C., 1996. Forest Stand Dynamics: Update Edition. John Wiley \& Sons, 672 New York, NY.

673 Palik, B.J., Ostry, M.E., Venette, R.C., Abdela, E., 2012. Tree regeneration in black ash (Fraxinus nigra) stands exhibiting crown dieback in Minnesota. For. Ecol. Manag. 269, 26-30. doi:10.1016/j.foreco.2011.12.020

Palik, B.J., Ostry, M.E., Venette, R.C., Abdela, E., 2011. Fraxinus nigra (black ash) dieback in Minnesota: Regional variation and potential contributing factors. For. Ecol. Manag. 261, 128-135. doi:10.1016/j.foreco.2005.03.013 partitioning among trees in forest stands along an ecological gradient in central Europe. Can. J. For. Res. 40, 370-384. doi:10.1139/X09-195 
692 Pretzsch, H., Dieler, J., 2010. The dependency of the size-growth relationship of Norway spruce

693 (Picea abies [L.] Karst.) and European beech (Fagus sylvatica [L.]) in forest stands on

694 long-term site conditions, drought events, and ozone stress. Trees 25, 355-369.

695 doi:10.1007/s00468-010-0510-1

696 PRISM Climate Group, 2015. PRISM climate data: Recent years (Jan 1981-June 2014) [WWW

697 Document]. Northwest Alliance Comput. Sci. Eng. URL

698 http://www.prism.oregonstate.edu/recent/ (accessed 1.11.15).

699 Puettmann, K.J., D’Amato, A.W., Kohnle, U., Bauhus, J., 2009. Individual-tree growth dynamics

700 of mature Abies alba during repeated irregular group shelterwood (Femelschlag) cuttings.

701 Can. J. For. Res. 39, 2437-2449. doi:10.1139/X09-158

702 R Core Team, 2013. R: A language and environment for statistical computing. R Foundation for 703 Statistical Computing, Vienna, Austria.

704 Rouvinen, S., Kuuluvainen, T., 1997. Structure and asymmetry of tree crowns in relation to local 705 competition in a natural mature Scots pine forest. Can. J. For. Res. 27, 890-902.

706 doi:10.1139/x97-012

707 Schwinning, S., Weiner, J., 1998. Mechanisms determining the degree of size asymmetry in 708 competition among plants. Oecologia 113, 447-455. doi:10.1007/s004420050397

709 Slesak, R.A., Lenhart, C.F., Brooks, K.N., D’Amato, A.W., Palik, B.J., 2014. Water table

710 response to harvesting and simulated emerald ash borer mortality in black ash wetlands in

711 Minnesota, USA. Can. J. For. Res. 44, 961-968. doi:10.1139/cjfr-2014-0111

712 Speer, J.H., 2010. Fundamentals in Tree Ring Research. University of Arizona Press, Phoenix, $713 \quad$ AZ.

714 Stephenson, N.L., Das, A.J., Condit, R., Russo, S.E., Baker, P.J., Beckman, N.G., Coomes, D.A., 
Lines, E.R., Morris, W.K., Rüger, N., Álvarez, E., Blundo, C., Bunyavejchewin, S., Chuyong, G., Davies, S.J., Duque, Á., Ewango, C.N., Flores, O., Franklin, J.F., Grau, H.R., Hao, Z., Harmon, M.E., Hubbell, S.P., Kenfack, D., Lin, Y., Makana, J.-R., Malizia, A., Malizia, L.R., Pabst, R.J., Pongpattananurak, N., Su, S.-H., Sun, I.-F., Tan, S., Thomas, D., van Mantgem, P.J., Wang, X., Wiser, S.K., Zavala, M.A., 2014. Rate of tree carbon accumulation increases continuously with tree size. Nature 507, 90-93.

Tardif, J., Bergeron, Y., 1993. Radial growth of Fraxinus nigra in a Canadian boreal floodplain in

USDA Natural Resources Conservation Service, 2013. Web Soil Survey [WWW Document]. response to climatic and hydrological fluctuations. J. Veg. Sci. 4, 751-758. doi:10.1111/j.1365-2486.2009.01990.x URL http://websoilsurvey.nrcs.usda.gov/app/ (accessed 9.10.15).

Valladares, F., Niinemets, Ü., 2008. Shade Tolerance, a Key Plant Feature of Complex Nature and Consequences. Annu. Rev. Ecol. Evol. Syst. 39, 237-257. doi:10.1146/annurev.ecolsys.39.110707.173506

Visser, H., 1995. Note on the Relation Between Ring Widths and Basal Area Increments. For. Sci. 41, 297-304.

Weiner, J., 1990. Asymmetric competition in plant populations. Trends Ecol. Evol. 5, 360-364.

Wykoff, W.R., 1990. A basal area increment model for individual conifers in the northern Rocky Mountains. For. Sci. 36. 
738 Zang, C., Biondi, F., 2013. Dendroclimatic calibration in R: The bootRes package for response

739 and correlation function analysis. Dendrochronologia 31, 68-74.

$740 \quad$ doi:10.1016/j.dendro.2012.08.001 
Table 1 . Summary statistics for live trees $\geq 10 \mathrm{~cm}$ diameter at breast height (DBH) in five multiaged Fraxinus nigra stands.

\begin{tabular}{lccccccc} 
& & \multicolumn{3}{c}{ Site } & \\
\cline { 3 - 6 } Measure & Kupcho & Lake & Round & Toimi & Waskish & \\
& Species & Run & Williams & Lake & Creek & Trail & Mean \\
\hline TPH x species & FRNI & 482 & 656 & 414 & 614 & 426 & 518.4 \\
& ABBA & 28 & 2 & 24 & 50 & 142 & 49.2 \\
& ULAM & 20 & 0 & 66 & 0 & 22 & 21.6 \\
& THOC & 0 & 28 & 0 & 78 & 0 & 21.2 \\
& BEAL & 0 & 74 & 0 & 28 & 0 & 20.4 \\
& PIGL & 38 & 0 & 0 & 2 & 18 & 11.6 \\
& TIAM & 50 & 0 & 4 & 0 & 0 & 10.8 \\
Total TPH & QUMA & 34 & 0 & 8 & 0 & 2 & 8.8 \\
TPH \% F. nigra & ACRU & 0 & 12 & 0 & 0 & 0 & 2.4 \\
Total BA & & 664 & 774 & 516 & 776 & 610 & 668 \\
BA \% F. nigra & & 73 & 85 & 80 & 79 & 70 & 77.3 \\
QMD & & 27.4 & 25.8 & 33.2 & 29.4 & 23.7 & 27.9 \\
Maximum diameter (cm) & & 69.1 & 90.2 & 95.2 & 77.9 & 83.7 & 84 \\
Average tree age (yr) & & 23.0 & 20.6 & 28.6 & 22.0 & 22.2 & 23.3 \\
Mean Precipitation (mm) & & 75.1 & 54.5 & 59.4 & 58.0 & 50.0 & 56.0 \\
Ponding duration (5 longest) & & 677 & 720.5 & 686.7 & 853.5 & 699 & 727.3 \\
\hline Not TPH & & 1 & 5 & 3 & 4 & 2 & 104.7 \\
\hline
\end{tabular}

Note: $\mathrm{TPH}=$ trees per hectare, $\mathrm{BA}=$ basal area, $\mathrm{QMD}=$ quadratic mean diameter. Species codes are as follows: FNRI=Fraxinus nigra, $\mathrm{ABBA}=$ Abies balsamea, ULAM=Ulmus americana, THOC=Thuja occidentalis, BEAL=Betula alleghaniensis, PIGL=Picea glauca, TIAM=Tilia americana, QUMA=Quercus macrocarpa, ACRU=Acer rubrum. Mean values include standard errors. 
Table 2. Summary of diameter-based competition indices.

\begin{tabular}{lllll} 
Index & Type & $\begin{array}{l}\text { Size } \\
\text { Symmetry }\end{array}$ & Equation & Source \\
\hline CI-1 & $\begin{array}{l}\text { distance } \\
\text { dependent }\end{array}$ & symmetric & $C I_{i}=\sum_{j=1}^{n} d_{j}$ & *Author adapted \\
CI-2 & $\begin{array}{l}\text { distance } \\
\text { dependent }\end{array}$ & symmetric & $C I_{i}=\sum_{j=1}^{n} \frac{d_{j}}{L_{i j}}$ & Rouvinen and \\
CI-3 & $\begin{array}{l}\text { distance } \\
\text { dependent }\end{array}$ & asymmetric & $C I_{i}=\sum_{j=1}^{n} \frac{\left(\frac{d_{j}}{d_{i}}\right)}{L_{i j}}$ & Kuuluvainen (1997) \\
CI-4 & $\begin{array}{l}\text { distance } \\
\text { dependent }\end{array}$ & asymmetric & $C I_{i}=\sum_{j=1}^{n} \frac{\left(\frac{d_{j}}{d_{i}}\right)}{L_{i j}}$ & Hegyi (1974) \\
CI-5 & $\begin{array}{l}\text { distance } \\
\text { dependent }\end{array}$ & asymmetric & $C I_{i}=\sum_{j=1}^{n} \frac{\left(\frac{d_{j}}{d_{i}}\right)^{2}}{L_{i j}}$ & Rouvinen and \\
CI-6 & $\begin{array}{l}\text { distance } \\
\text { independent }\end{array}$ & asymmetric & $C I_{i}=\sum_{j=1}^{n}\left(\frac{d_{j}}{d_{i}}\right)^{2}$ & Kuuluvainen (1997) \\
Lorimer & $\begin{array}{l}\text { distance } \\
\text { independent }\end{array}$ & asymmetric & $C I_{i}=\sum_{j=1}^{n} \frac{d_{j}}{d_{i}}$ & Rouvinen and \\
distance & asymmetric & $C I_{i}=\sum_{j=1}^{n}\left(d_{j}\right)^{2} * 0.00007854$ & Kuuluvainen (1997) \\
independent & & Author adapted \\
\hline
\end{tabular}

Note: $*$ = Adapted by authors based on indices in Rouvenin and Kuuluvainen (1997).

Indicated is whether competitors are weighted by distance and treated as symmetric or asymmetric in terms of diameter, equations, and in original publications where applicable.

Symbols are as follows: $C I_{i}$ is the competition index $(C I)$ for the individual target tree $(\mathrm{i})$; $d_{j}$ is the diameter $(d)$ of a given competitor $(j)$; $d_{i}$ is the diameter of target tree $(i), L_{i j}$ is the distance $(L)$ between target $(i)$ and competitor $(j)$. Indices are calculated for $(j=1)$ where $(j \neq i)$. 
Table 3. Summary of null and confidence set models for individual sites ( $\triangle \mathrm{AIC} \leq 8)$, showing relative support for both null and most probable model by competition index (CI) across sites.

\begin{tabular}{|c|c|c|c|c|c|c|c|c|c|}
\hline Site & Model & DBH & $\mathrm{CI}$ & $\begin{array}{l}\text { DBH x } \\
\text { CI }\end{array}$ & AIC & $\triangle \mathrm{AIC}$ & $\begin{array}{c}\text { Relative } \\
\text { Likelihood }\end{array}$ & Weights & $\begin{array}{c}\text { Evidence } \\
\text { Ratio }\end{array}$ \\
\hline KR & Wykoff & $0.61 * * *$ & $-0.26 * * *$ & $-0.14 * * *$ & 180.35 & 0.00 & 1.00 & 0.76 & 1.00 \\
\hline KR & Lorimer & $0.41 * * *$ & $-0.46 * * *$ & $-0.17 * * *$ & 183.45 & 3.10 & 0.21 & 0.16 & 4.71 \\
\hline $\mathrm{KR}$ & CI-6 & $0.47 * *$ & $-0.40 * * *$ & $-0.16 * * *$ & 185.04 & 4.69 & 0.10 & 0.07 & 10.43 \\
\hline $\mathrm{KR}$ & Null & --- & --- & --- & 368.12 & 187.77 & 0.00 & 0.00 & $5.94 \mathrm{E}+40$ \\
\hline LW & DBH & $0.80 * * *$ & --- & --- & 369.40 & 0.00 & 1.00 & 0.63 & 1.00 \\
\hline LW & Lorimer & $0.98 * * *$ & 0.13 & $0.12 * *$ & 371.03 & 1.63 & 0.44 & 0.28 & 2.26 \\
\hline LW & Wykoff & $0.95^{* * *}$ & 0.11 & $0.11 *$ & 373.24 & 3.84 & 0.15 & 0.09 & 6.82 \\
\hline LW & Null & --- & --- & --- & 556.14 & 186.74 & 0.00 & 0.00 & $3.55 \mathrm{E}+40$ \\
\hline RL & CI-6 & $0.55^{* *}$ & $-0.41 *$ & $-0.28 * * *$ & 169.45 & 0.00 & 1.00 & 0.63 & 1.00 \\
\hline RL & Lorimer & $0.72 * * *$ & -0.24 & $-0.28 * * *$ & 170.65 & 1.20 & 0.55 & 0.44 & 1.82 \\
\hline RL & Null & --- & --- & --- & 285.86 & 116.41 & 0.00 & 0.00 & $1.07 \mathrm{E}+23$ \\
\hline $\mathrm{TC}$ & Wykoff & $0.75^{* * *}$ & 0.28 & $-0.36 * * *$ & 365.60 & 0.00 & 1.00 & 0.47 & 1.00 \\
\hline $\mathrm{TC}$ & Lorimer & 0.30 & -0.26 & $-0.31 * * *$ & 366.00 & 0.40 & 0.82 & 0.39 & 1.22 \\
\hline $\mathrm{TC}$ & CI-6 & $1.12 * * *$ & $0.52 *$ & $-0.28 * * *$ & 368.34 & 2.74 & 0.25 & 0.12 & 3.94 \\
\hline $\mathrm{TC}$ & CI-5 & $0.43 * * *$ & -0.18 & $-0.23 * * *$ & 372.30 & 6.70 & 0.04 & 0.02 & 28.50 \\
\hline $\mathrm{TC}$ & Null & --- & --- & --- & 425.16 & 59.56 & 0.00 & 0.00 & $8.58 \mathrm{E}+12$ \\
\hline WT & Wykoff & --- & $-0.67 * * *$ & --- & 223.70 & 0.00 & 1.00 & 1.00 & 1.00 \\
\hline WT & Null & --- & --- & --- & 287.91 & 64.21 & 0.00 & 0.00 & $6.70 \mathrm{E}+13$ \\
\hline All & CI-6 & $0.47 * * *$ & $-0.23 *$ & $-0.13 * * *$ & 1327.60 & 0.00 & 1.00 & 0.54 & 1.00 \\
\hline All & Lorimer & $0.52 * * *$ & $-0.21 *$ & $-0.12 * * *$ & 1328.66 & 1.06 & 0.59 & 0.47 & 1.70 \\
\hline All & Wykoff & $0.54 * * *$ & $-0.19 * * *$ & $-0.07 * *$ & 1330.28 & 2.68 & 0.26 & 0.16 & 3.82 \\
\hline All & Null & --- & --- & --- & 1840.15 & 512.55 & 0.00 & 0.00 & $3.42 \mathrm{E}+221$ \\
\hline
\end{tabular}

Note: Model refers to the formula of CI used; see Table 2 for details. DBH (diameter at breast height), CI, and DBH x CI columns display standardized partial regression coefficients (beta weights) of model terms, when present. Also provided are Akaike's information criterion (AIC) model comparisons (Burnham and Anderson 2002) within sites and models comparing CI across sites. Symbols are as follows: AIC, difference compared to best-fitting model ( $\triangle \mathrm{AIC}$ ); relative likehood; Akaike weights (weights); evidence ratio. Akaike weights calculated for models within the confidence sets also incorporate null intercept models. See Figure 1 for site abbreviations. 
Table 4. Summary of confidence set SGR models for individual sites $(\Delta \mathrm{AIC} \leq 8)$.

\begin{tabular}{cccccc} 
Site & Model & Year & SGR Type & AIC & $\Delta$ AIC \\
\hline KR & Null & --- & --- & -372.84 & 0 \\
KR & Year & $-0.004 * * *$ & --- & -366.86 & 5.98 \\
RL & Null & --- & --- & -374.46 & 0 \\
RL & Type & --- & $0.201 * * *$ & -374.37 & 0.09 \\
TC & Null & --- & --- & -386.40 & 0 \\
TC & Year & $-0.004 * * *$ & --- & -380.08 & 0 \\
TC & Type & --- & 0.060 & -382.30 & 2.22 \\
WT & Type & --- & 0.083 & -341.20 & 0 \\
WT & Null & --- & --- & -344.60 & 3.40 \\
\hline
\end{tabular}

Note: Potential model included SGR type (F. nigra-only or all species) and year (1952-2011). Columns display unstandardized regression coefficients, when present. Models are ranked within sites in terms of AIC support, with models presented in order of declining support. See Table 3 for explanation of symbols related to AIC. See Figure 1 for site abbreviations. Lake Williams is not included as there was no AIC support for either a time or species effect on SGR. * significant at $\mathrm{p}<0.05 ; * *$ significant at $\mathrm{p}<0.01 ; * * *$ significant at $\mathrm{p}<0.001$ 


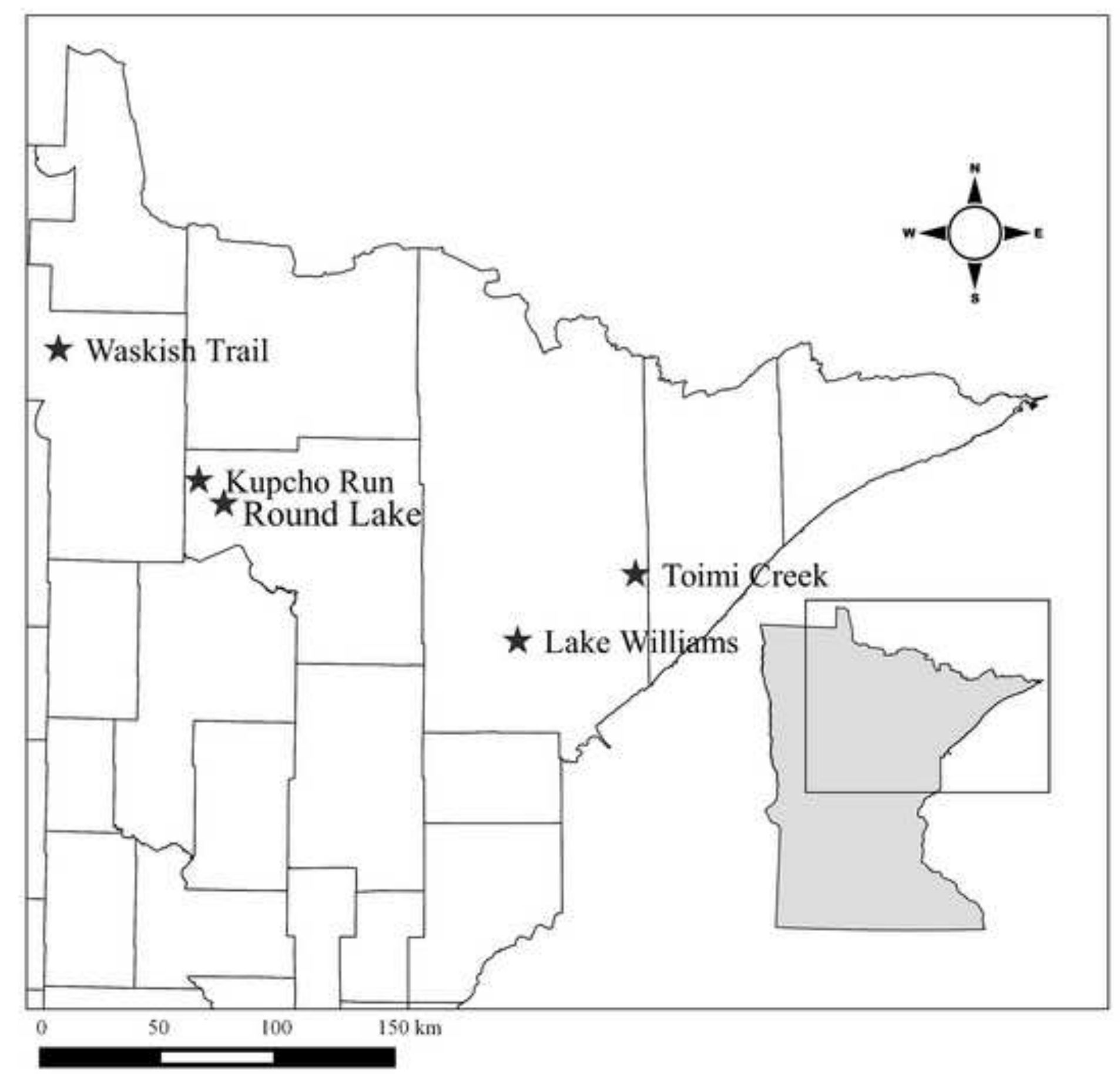




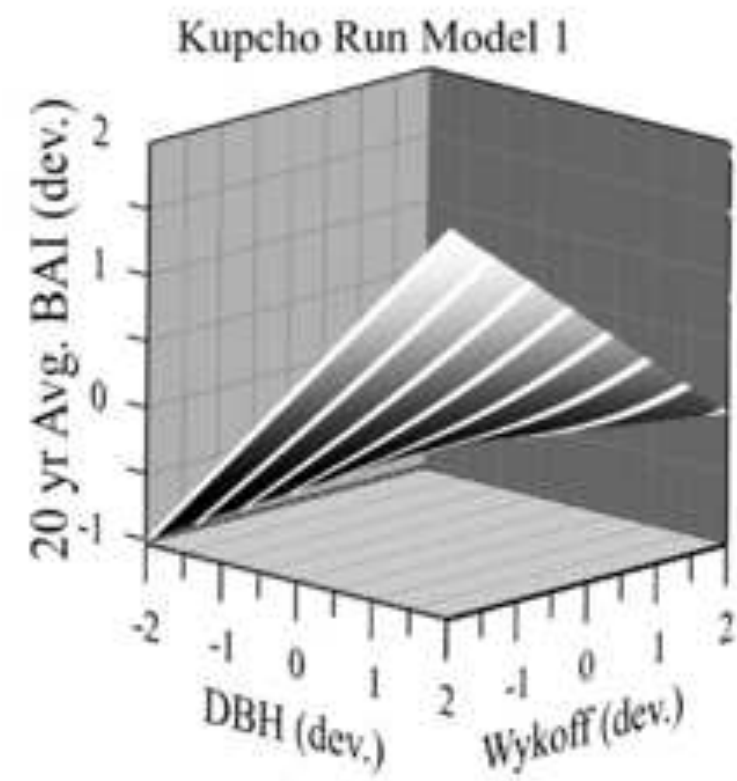

Lake Williams Model 2

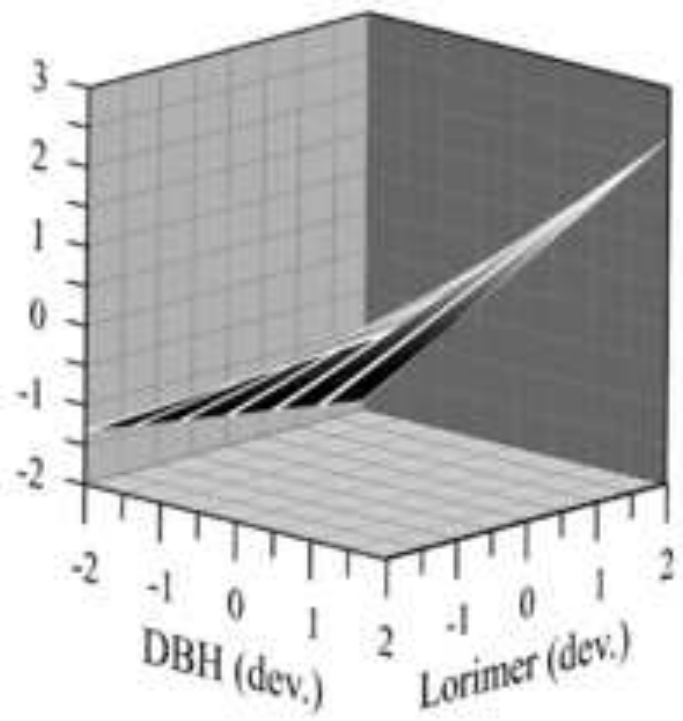

Toimi Creek Model 1

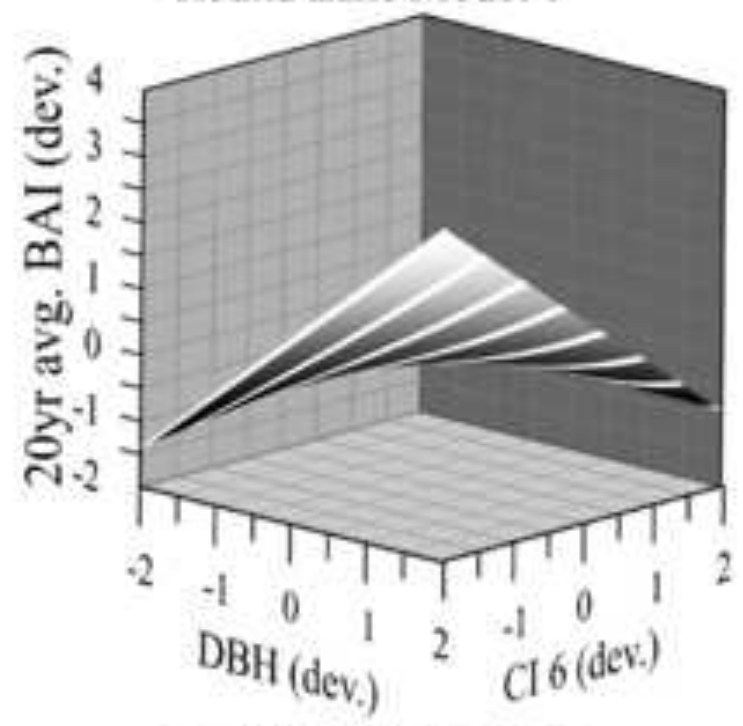

Waskish Trail Model 2
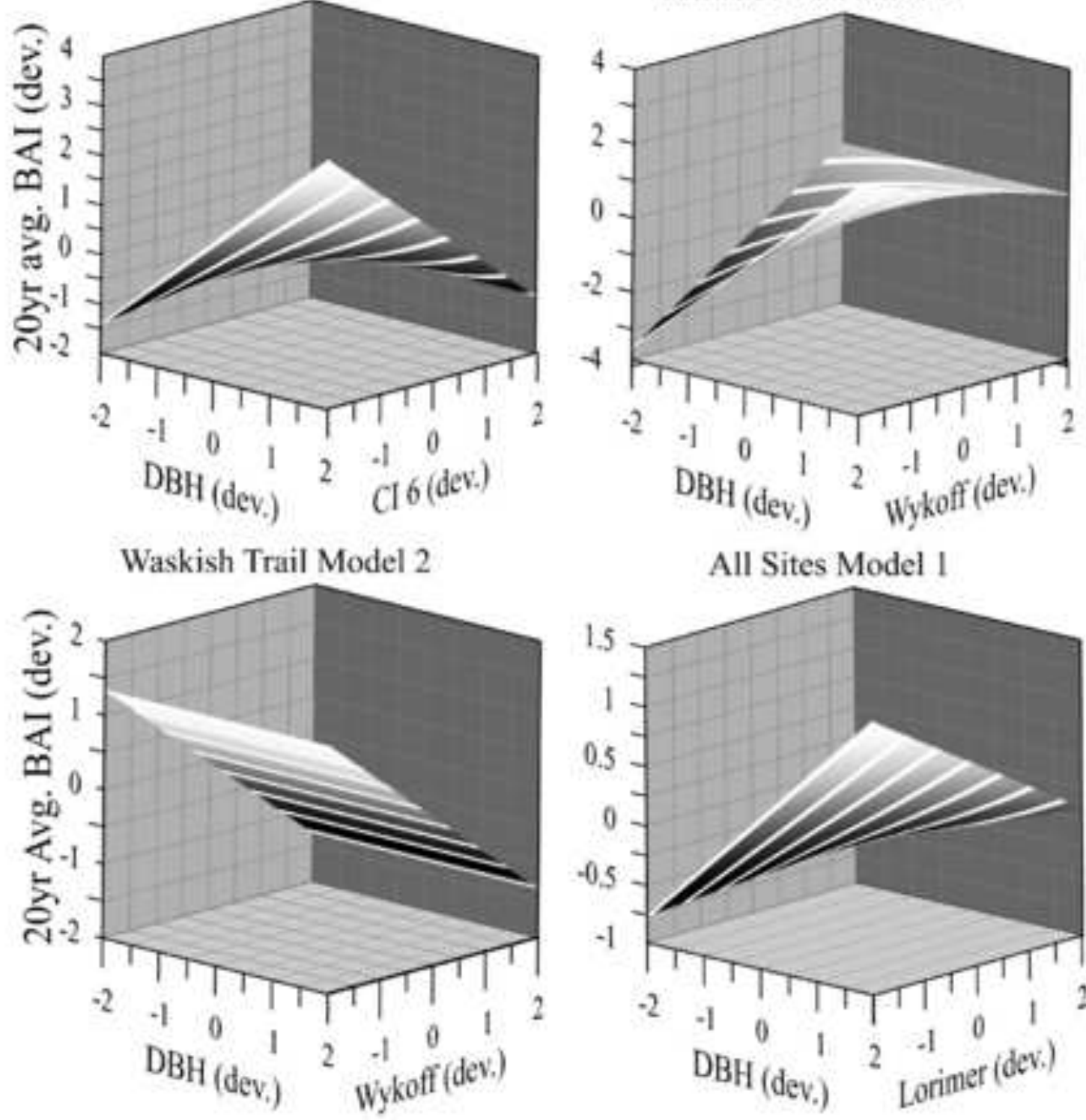

All Sites Model I

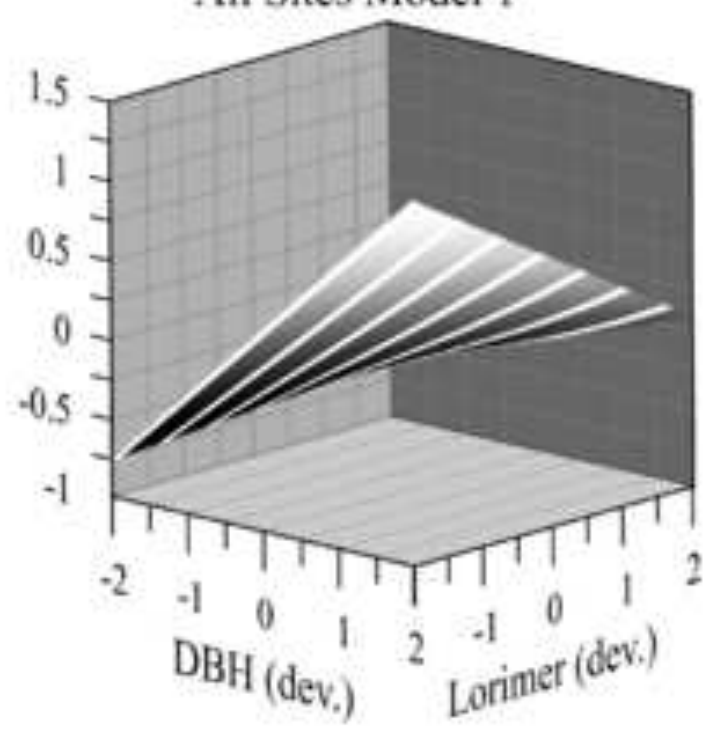



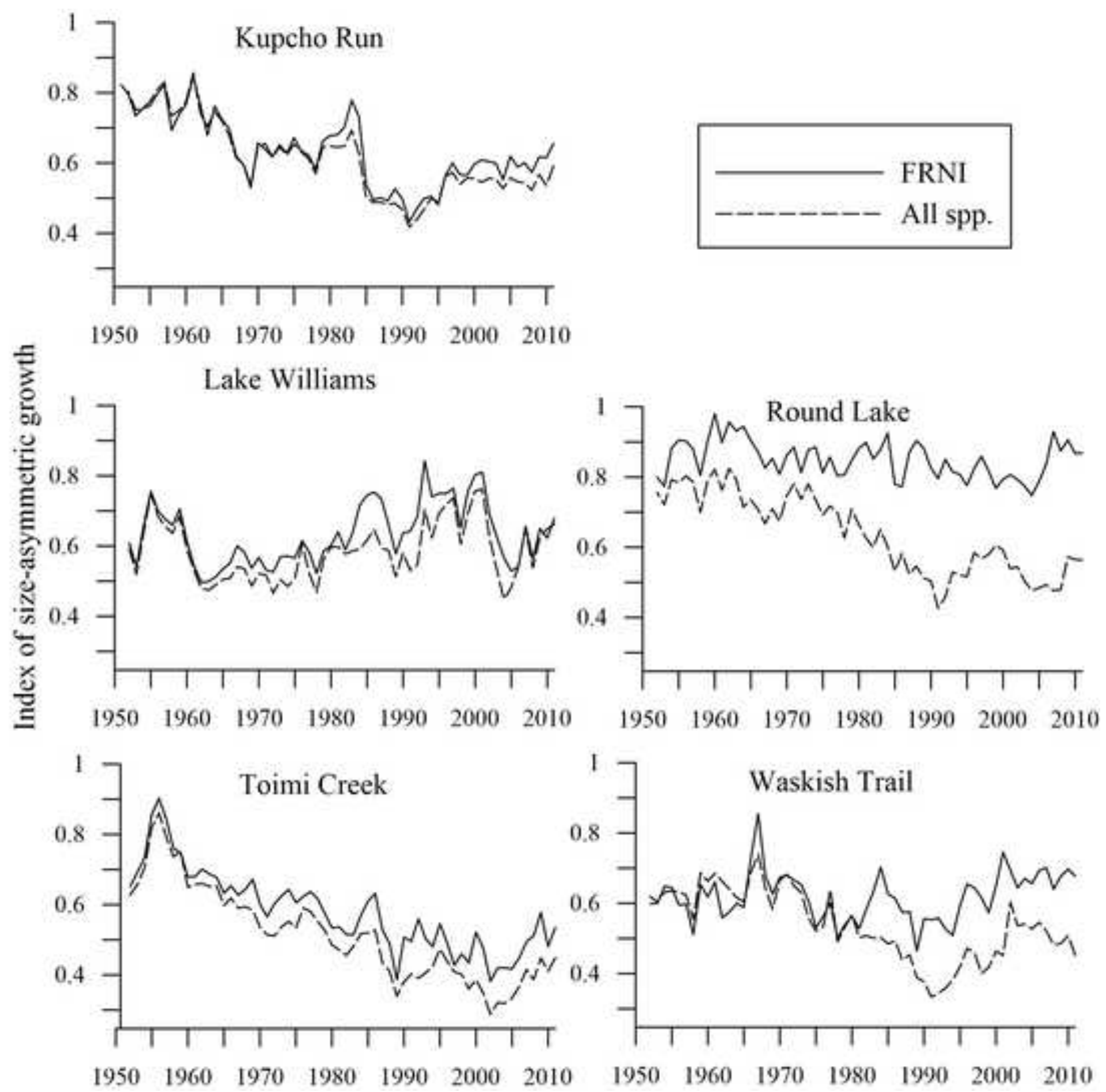


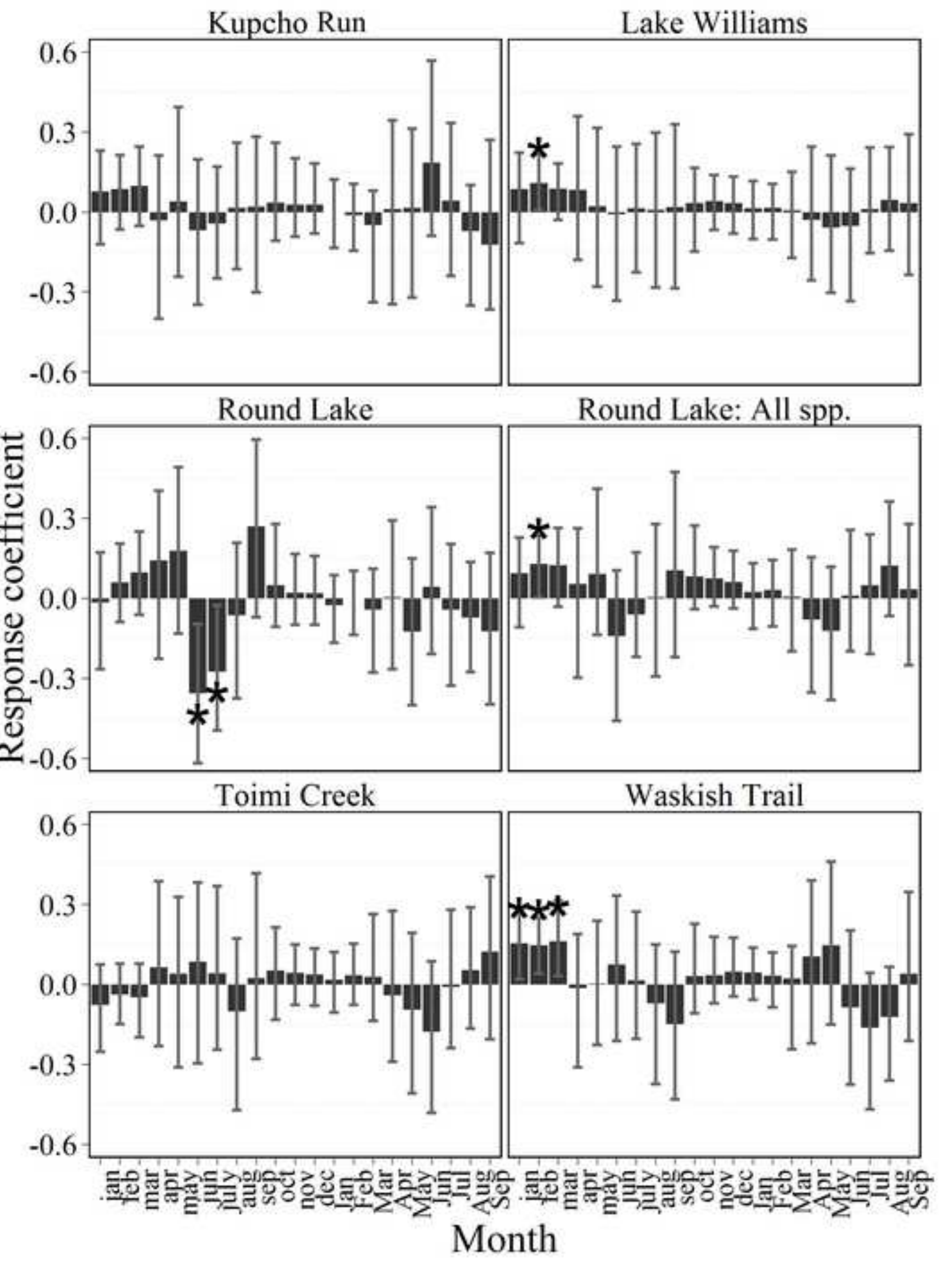

Month 
Figure 1. Map depicting location of the five Fraxinus nigra study sites in northern Minnesota USA: Kupcho Run (KR), Lake Williams (LW), Round Lake (RL), Toimi Creek (TC), and Waskish Trail (WT).

Figure 2. Response surfaces for the most highly supported Fraxinus nigra growth model in the confidence set for 5 multi-aged $F$. nigra stands. In the case of Lake Williams, the second-best supported model is displayed for illustration; the best-supported model at Lake Williams was a simple function of DBH. Basal area increment increases from bottom to top on the $\mathrm{Y}$ axis. The $\mathrm{X}$ axis displays DBH with standard deviation (dev.), while the $\mathrm{Z}$ axis displays competition index (CI) with standard deviation (dev.). Variables were centered and standardized following transformations. BAI for Kupcho Run, Round Lake, and Toimi Creek was square-root transformed. All other response and predictor variables were log-transformed.

Figure 3. Trends in Metsaranta and Lieffers (2010) size-growth relationship (SGR) index for 5 multiaged Fraxinus nigra stands, 1952 - 2011. The SGR is provided separately for each site based on all-species data and calculated separately for Fraxinus nigra. SGR values $<1$ indicate inverse size-asymmetric growth, values $>1$ indicate size-asymmetric growth, and values $=0$ indicate size-symmetric growth.

Figure 4. Relationships between spline-standardized Metsaranta and Lieffers (2010) size-growth relationship (SGR) index and Palmer's (1965) drought severity index (PDSI) based on bootstrapped response function analysis. Analysis based on annual SGR values and monthly PDSI, 1952-2011. Response functions were calculated separately for all-species and for F. nigraonly SGR. Positive coefficients indicate increased size-asymmetry of growth in wet years; negative relationships indicate reduced tree growth in wet years. Response functions for allspecies SGR are omitted for brevity due to showing responses equivalent to $F$. nigra-only SGR except at Round Lake, where responses differed. Months shown in lower case are from previous year. * significant at $\mathrm{p}<0.05$; **significant at $\mathrm{p}<0.01$; ***significant at $\mathrm{p}<0.001$ 